\title{
La Cruzada de los Niños: Memoria, Actualidad y Guiños Históricos ${ }^{1}$
}

\section{The Children's Crusade: Memory, Present Times and Historical Hints.}

\author{
Patricio Rodríguez-Plaza \\ Escuela de Teatro \\ Pontificia Universidad Católica de Chile \\ rodriguezplaza@uc.cl
}

Resumen - El presente texto se ubica en el supuesto lugar de un espectador ordinario, escudriña críticamente en las problemáticas que expresa y expone la obra $L a$ cruzada de los niños, menos desde el texto dramático que desde las dimensiones espectaculares que dotan y construyen sentido teatral: escenografía, vestuario, iluminación, diseño sonoro.

Palabras clave: Texto espectacular, recepción teatral, marginalidad urbana.

Abstract - The following is a text that, placing itself in the spot of a regular spectator, critically examines the problematical issues immersed in the play La Cruzada de los Niños. The text will construct the analysis using mainly the dimensions of the spectacle that build up a theatrical sense rather than focusing only on the play's text. It will consider elements such as the scenography, costume design, lighting, and theatrical acoustics.

Keywords: Text and spectacle, reception of theater, urban marginality.

Artículo que tiene como base la presentación del autor en el I Seminario Internacional Teatro, Memoria, Historia, Escuela de Teatro, Pontificia Universidad Católica de Chile, 21 a 23 de octubre de 2008. 


\section{TEATRO, MEMORIA E HISTORIA}

Maldición de la memoria, me acuerdo de todo, expresa el expósito al renacer desde el útero alcantarilla en donde había sido arrojado, luego de su primer nacimiento. Así, sin más, la obra La cruzada de los niños - cuya puesta en escena le pertenece a un trabajo inserto en el marco del Laboratorio Teatral de la Escuela de Teatro de la Pontificia Universidad Católica de Chile bajo la dirección de Macarena Baeza de la Fuente y su texto a Marco Antonio de la Parra- nos plantea, desde el inicio, un entrecruzamiento consistente y abierto a distintas dimensiones de la cultura. Entrecruzamiento entre la pequeña, dramática y hasta cruel historia de unos niños inmersos a regañadientes por entremedio de los recovecos y purgatorios urbanos; la historia como alucinación colectiva de Occidente y la memoria comunitaria, de un Tercer Mundo que resuelve su percepción desviada del presente, al no ver lo que es aquí lo más evidente: la pobreza, la prostitución, el abuso, sin detenerse, muchas veces en el hecho de que ahí hay también solidaridad y cariño derramado en medio del abandono.

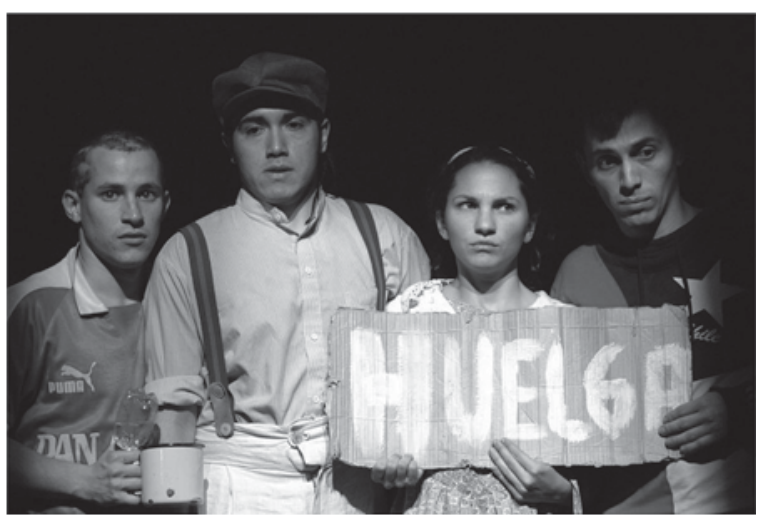

Fotografía 1: Prensa UC.

Intento desde aquí, trazar una muestra de aquellas problemáticas, menos desde el texto dramático o las ideas y contenidos expuestos artísticamente, que desde las dimensiones espectaculares que dotan y construyen sentido teatral: escenografía, vestuario, iluminación, diseño sonoro, que son los elementos que le llegan finalmente al espectador menos letrado, aunque no por ello menos involucrado. ¿Por qué de tal perspectiva? Simplemente porque son esos sistemas semióticos los que son percibidos directamente por el espectador y porque además son ellos los que constituyen el sentido creativo más allá incluso de las ideas prearmadas que pueden estar en la base de los textos materiales y espectaculares, en los que se vehicula fenomenológicamente lo teatral.

Echando mano a la determinación conceptual de Pierre Baqué, para quien la investigación en artes - que yo extiendo al teatro- se diferencia entre una investigación sobre las artes, en cuyo caso el objeto de estudio existe, está allí a los ojos del investigador; de una segunda que él entiende como una investigación por las artes, la que concierne a aquellos que pertenecen al mundo del arte, más particularmente a la creación artística y 
finalmente de una investigación en artes que vincula las dos anteriores, me permito una mirada crítica, que imaginando un espectador desde la tercera definición, exponga sus sensaciones intelectuales, gatilladas por una puesta en escena como la que nos ocupa.

Pierre Baqué está, evidentemente, refiriéndose a una pesquisa desde el nivel de la producción (intelectual y artística), mientras que lo que expongo en este caso es una crítica desde el espectador; teniendo en cuenta que tal espectador está inserto en el concepto más amplio de público, que, como sabemos, alude a aquella noción que permite y legitima las artes modernas.

Es decir, que se trata de la recepción en cuyo centro aparecen los horizontes de expectativa y de experiencia, en tanto reconstitución de las perspectivas que construye el público (estéticas, ideológicas, culturales) al ubicar el espectáculo en la evolución de la historia de tal disciplina, concibiéndolo como respuesta a un conjunto de preguntas aparecidas en todas las etapas de la realización de la escenificación, así como cargándola de una dimensión de gozo, cuyas estructuras más hondas se arman en la generación subjetiva, personal e universal (diría Kant) de significación.

El primer asunto es luego, la percepción y la memoria de un espectador que entrelaza ambos horizontes para asistir al activamiento estético que trabaja justamente la memoria como una herramienta perceptual de primera línea.

En fin, intento un trabajo crítico con aquello que Nelly Richard llamaría con el sentido y no sobre el sentido, llevándolo, como digo, al nivel de un espectador comprometido, cautivo, interesado; un productor simbólico que es capaz de manufacturar creativa y dialécticamente desde lo que el teatro le ofrece como espectáculo artístico, con la conjunción de la mirada constructora de teatralidad de la que él es capaz.

Sigo para ello la estructura, no solo de la puesta en escena, sino también de los prolegómenos que se instalan mientras el público está llegando y acomodándose en la sala. Esto porque la obra misma, aquella convención que tiene un punto de partida cuando se apagan las luces y se abre el telón (asunto convencional que ha sido, por lo demás, desarmado de muchas maneras en el teatro contemporáneo), acá no existe. Los espectadores entran a la sala y se ven enfrentados al juego de pelota de los actores y al sonido de la música juvenil que los recibe y que, por un segundo, los desconcierta. Más aún, cuando alguno de los protagonistas baja a las butacas a jugar con algún espectador conocido personalmente por el actor - el que evidentemente no deja de actuar-, el desconcierto es aún más marcado. ¿Estará hablándome a mí en cuanto asistente a la obra o en tanto conocido del actor? Todo ello es remarcado por el hecho de que tal juego es practicado corporal y activamente: el actor-personaje se sube literalmente encima de algún espectador, le grita a los otros personajes que llegó tal o cual tío (que es como suelen llamarle los niños a los mayores en Chile), le tira la pelota para que la reciba y la devuelva.

¿Por qué de tal decisión de análisis crítico? Simplemente porque ese momento desborda la obra misma, aunque paradójicamente es una introducción a ciertos guiños biográficos de las personalidades del elenco y del equipo que arma la producción a través de la proyección en una pantalla instalada en el fondo del escenario, de fotografías de sus distintas infancias y juventudes. Mientras la actriz Manuela Martelli nombra allí mismo a los actores por sus nombres propios o sus chapas: Guille (que en realidad es José Manuel Aguirre), Pinilla de quien se dice su apellido (como en el colegio chileno en el que los varones solíamos — no sé cómo será ahora- llamarnos por el apellido), Dani que en realidad se llama Daniel Gallo. 
La aparición de dichas fotografías es la primera entrada en la historia personal, no solo de los actores, sino de todo el equipo que ha participado en la representación: acá Macarena Baeza, Sara Pantoja y Daniel Gallo, allá Ramón López, Mario Costa y Carlos Espinoza por nombrar solo algunos.

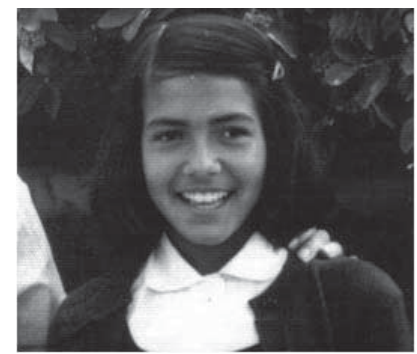

Fotografía 2: archivo personal Sara Pantoja

Al ritmo del rap, se escucha como parte del diseño sonoro, entre otros a la cantante española Mala Rodríguez y algunas canciones que hoy son la actualidad - y pertenecen una vez más a la usanza de la juventud-, situándonos en el tiempo presente que, siguiendo la vieja frase de Marx, será también desvanecido en el aire, convirtiéndose, tarde o temprano, en lo pasado de moda.

Al final de esta preparación, en la que sentimos una desconcertante ambigüedad entre lo espectacular como representación convencional y lo que Richard Schechner ha llamado un texto performativo (Féral, 2004), deviene un silencio casi total que anticipa la aparición en pantalla de unos letreros que informan al público acerca del hecho histórico, al parecer nunca suficientemente probado, de la cruzada medieval llevada a cabo por niños y adolescentes de Francia y Alemania en el año de 1212. Niños y adolescentes, guiados por la idea de que lo que no habían podido hacer los adultos, pretendieron liberar la ciudad de Jerusalén de manos sarracenas, en cuanto dato atravesado por uno de los tantos desvaríos colectivos que suele insertar la historia y sobre todo la historiografía. Niño se decía puber en latín y era una expresión que podía usarse hasta con personas de 28 años, al tiempo que los cronistas medievales asociaban muchas veces a estos niños cruzados con la edad de 12 años, debido al pasaje bíblico en el que Jesús aparecía escapándose de su casa a esa edad, a la vez que asociaban pureza con pobreza.

$\mathrm{Y}$ es en esta parte en que simultáneamente se produce un cierre de aquella performatividad y una apertura con la canción interpretada por Amapola Reyes y Martín Muñoz, quienes en vivo y con guitarra y bajo, vestidos con el uniforme escolar chileno, señalan el orden y las movilizaciones a las que de tiempo en tiempo nos conducen los chicos, que sin abandonar la moda, dejan sus estelas crudas de paso firme y decidido por los vericuetos de la realidad social y política.

¿Pero qué es y qué ha sido La Cruzada de los niños? En parte, el resultado de un trabajo que se sitúa en el marco de una experimentación universitaria, de un trabajo por el teatro podríamos decir, parafraseando al mismo Pierre Baqué. «Un espacio de creación libre, con vocación académica que [ha permitido] a profesores y estudiantes poner a prueba algunas intuiciones escénicas transformándolas en una especie de hipótesis de trabajo», dirá Inés Stranger (Cuadernos TEUC). Sí, una hipótesis que ha posibilitado el 
desenvolvimiento creativo, involucrando herramientas e ideas, avances y retrocesos en un camino que no deseche lo aleatorio, lo accidental ni menos aún lo conseguido oblicuamente en la experimentación e investigación interdisciplinaria. Desde el teatro hacia la teatralidad, desde la estética a los subtextos históricos o sociológicos; en fin, desde la voz técnicamente manejada como expresión, a la dramaturgización propuesta por los propios actores una vez que se ha andado, como en este caso, en la calle y debajo de los puentes para percibir lo dramático de la vida y de la muerte social.

Por otra parte, es una obra de teatro que ha recorrido un camino itinerante, abriendo y cerrando especialmente sus posibilidades materiales. Desde una sala de clases de la Escuela de Teatro de la Universidad Católica, hasta la sala Eugenio Dittborn del TEUC; desde Santiago de Chile a Taltal; desde Mendoza a Puebla y desde allí a Bruselas; viviendo, como es natural, unos cambios de público y unos movimientos de maniobras escenográficas para poder, justamente, deambular, sumándole un recambio no menor de actriz: de Manuela Martelli a Ignacia Agüero.

Pero también se trata del trabajo de una directora joven y brillante que ha incursionado esencialmente en el teatro barroco, que se ha involucrado con las monjas coloniales, con la historia que nos viene dada por el pasado latinoamericano, el que convierte a los clásicos españoles en sus propios clásicos. Una mujer de teatro que, sin embargo, ha sabido hacer con esta Cruzada un paso hacia la contemporaneidad más eficaz; atrayendo hacia el nivel de la expresión todo un andamiaje de citas biográficas y de diseño de carácter holístico para con esta escenificación.

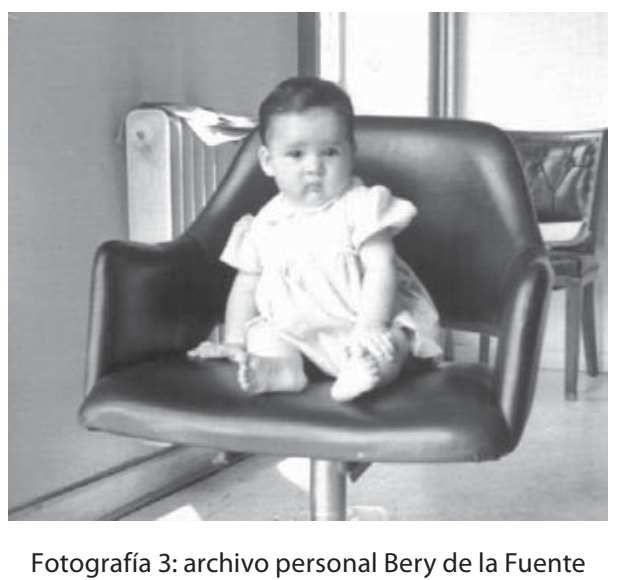

Un trabajo que confunde con gracia y creatividad - al menos en un principio- la representación y la puesta en escena (Pavis) estableciendo una tensión a la que no se puede ser indiferente, producto, al menos en parte, de su condición de profesora, es decir, de alguien dedicada a enseñar, a formar, a compartir un quehacer lleno de titubeos y de inseguridades, de distancias interpersonales y acercamientos sentimentales. Una personalidad que se mueve con soltura entre las directrices que significan la dirección teatral y el quehacer gestual y creativo de los actores, en cuyo mundo profesional ha sido ella misma formada, lo que le permite, pienso, la posibilidad de descentrar lo actoral de lo biográfico, lo representacional de lo performativo. 
Desde todo esto, La cruzada de los niños es, me parece, una puesta en obra de una dimensión fuerte de lo social-histórico, que ha sido definido, con no poca belleza, como «lo colectivo anónimo, lo humano impersonal que llena toda formación social dada, pero que también la engloba, que ciñe cada sociedad entre las demás y las inscribe a todas en una continuidad en la que de alguna manera están presentes los que ya son, los que quedan fuera e incluso los que están por nacer» (Castoriadis, 185). Todo ello, evidentemente desde el teatro, colocado en los ejes protagónicos de la inhalación de una sustancia, aparentemente barata, con la cual los cuatro protagonista se drogan, manteniéndose en una especie de limbo, y la profusa aparición de una bandera chilena, con lo cual la obra produce una filiación con las artes plásticas chilenas contemporáneas. La bandera chilena, que como hemos anotado por ahí, ha aparecido, una y otra vez, como fundamento creativo de muy variadas propuestas performativas: de José Balmes a Carlos Leppe; de Carlos Altamirano a Voluspa Jarpa (Bahamonde, Farriol, Rodríguez-Plaza; 2005).

\section{LOS CUATRO PERSONAJES}

\section{EL EXPÓSITO}

Yo no merecía eso, yo no merecía nada, yo no había alcanzado a portarme mal, ni bien. Tenía la memoria terrible de los [...] asesinados: esa es una de las primeras frases que inicia la entrada del expósito en esta narración hecha de partes de un todo. La memoria que es conducida hacia ese inicio de la obra en el que un juego de luces transversales y en movimiento rotatorio y horizontal indica la metáfora del niño botado, arrojado a la alcantarilla con el fin expreso de ser olvidado, borrado, aunque sin atreverse a ser muerto por aquellos que lo han vomitado.

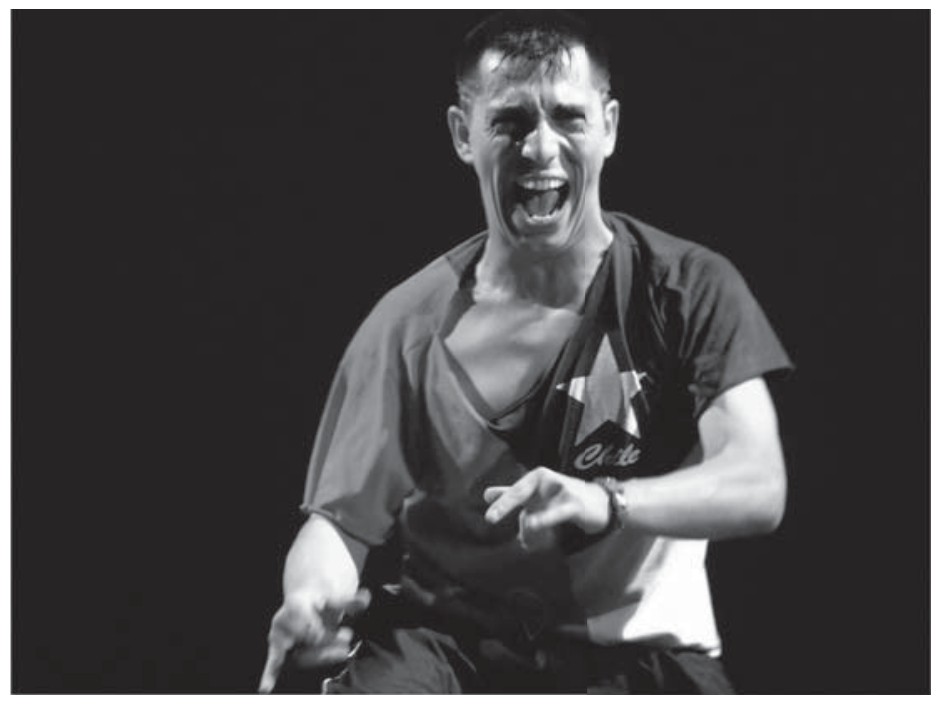

Fotografía 4: Carlos Vázquez Lomelí 
La luz blanca lo atraviesa, pero también esa luz lo ilumina desde abajo, desde el fondo de la ciudad que lo escupe, para lanzarlo paradójicamente hacia su exterior, hacia las redes de sus ruidos y ensoñaciones. El expósito sale a la superficie mientras esta luz blanca y cruda se acompasa con los ruidos de la ciudad, con la voz tenue y los acordes simples de una música de profunda melancolía. Es él quien se encargará de repetir y reiterar la expresión chilena igüena guacho! que bruscamente nos va a permitir el movimiento desde la gran historia o los grandes parlamentos de la ciudad y de Occidente hacia la pequeña, situada y local historia de este país ubicado literal y topográficamente en el fin del mundo. Güena guacho es una de las acepciones inverosímiles y absurdas en la que los chilenos solemos reconocernos al nombrarnos y escucharnos en la condición de bastardía de la que casi nadie está libre.

Y de pronto el expósito canta, se mueve, baila en una coreografía grupal, produciendo un primer destello de farándula en medio de la memoria, recordándonos de paso que la primera acepción que de farándula nos entrega el diccionario de la Real Academia Española, es justamente la de profesión y ambiente de los actores. Canta y baila al compás de los otros tres personajes, en donde los niños hombres - como decimos en nuestro paísestán vestidos con camisetas de equipos de fútbol o como en el caso del expósito, con una camisa tricolor que tiene estampada una estrella en el lugar más cercano al corazón y que él ama.

\section{LA NIÑA QUE VENDÍA FLORES}

La niña vende flores, flores por unidad, pero también en ramos. Ella es una pequeña ramera (denominación medieval de la prostituta) de vestido diminuto y medias rojas por entremedio de las cuales se adivinan unas formas que apenas saben de intercambios sexuales, aunque sí del amor por el Carlos.

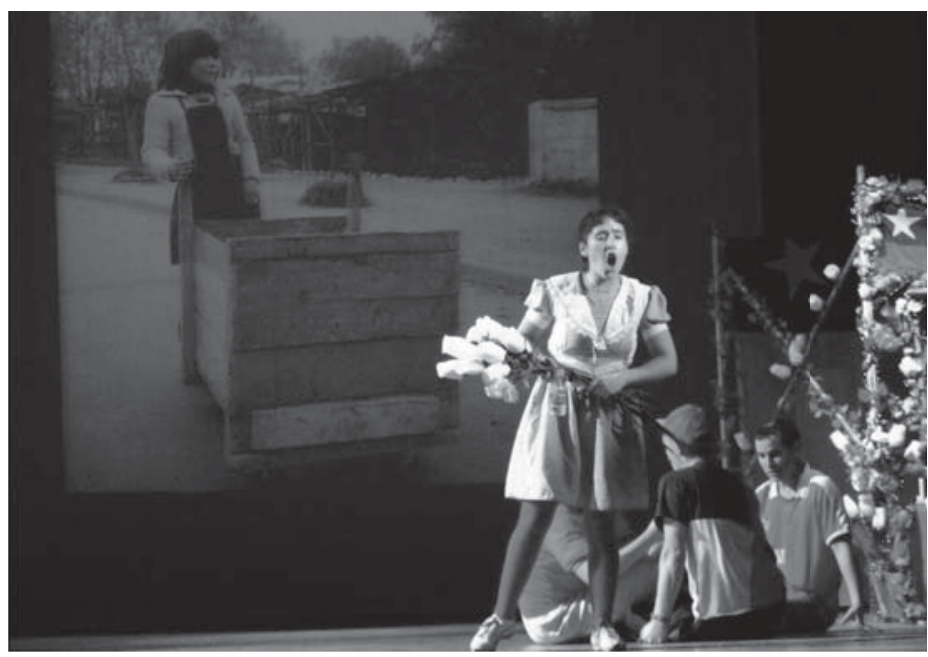

Fotografía 5: Carlos Vázquez Lomelí 
La niña juega con su propia niñez, con sus ensoñaciones más tenues, haciéndole cada vez una nueva mueca a Dios y a la Patria, a esas entidades que sobre todo entre nosotros los latinoamericanos se entrelazan con la historia finalmente.

Se trata de un Dios mágico, al alcance de la mano, a quien se le ruega, pero también, a quien se le pide y se le exige desde un altar de carretera, desde una animita que se yuxtapone, se superpone y hasta se inserta en este mundo paralelo en el que se encuentran estos niños. Una animita animada, tanto por la imagen de la Virgen convertida en diosa y madre, vestida con aquellos ropajes anacrónicos, pero también tan actuales para quienes nada tienen.

Pero la animita se viste también de fútbol, de banderines, de insignias y de velas baratas y hasta de un frontis neoclásico; igualmente de botellas transparentes llenas de agua, de esa agua cristalina, que pese a los tratamientos que ha sufrido a través (nuevamente) de la historia y a pesar de los recipientes plásticos que aquí la contienen, sigue trayéndonos una cierta idea de lo ancestral, de la vida misma, tejida en este caso con lo cotidiano, con la muerte de Carlos, que es en definitiva a quien se evoca, se le ruega y se le exige.

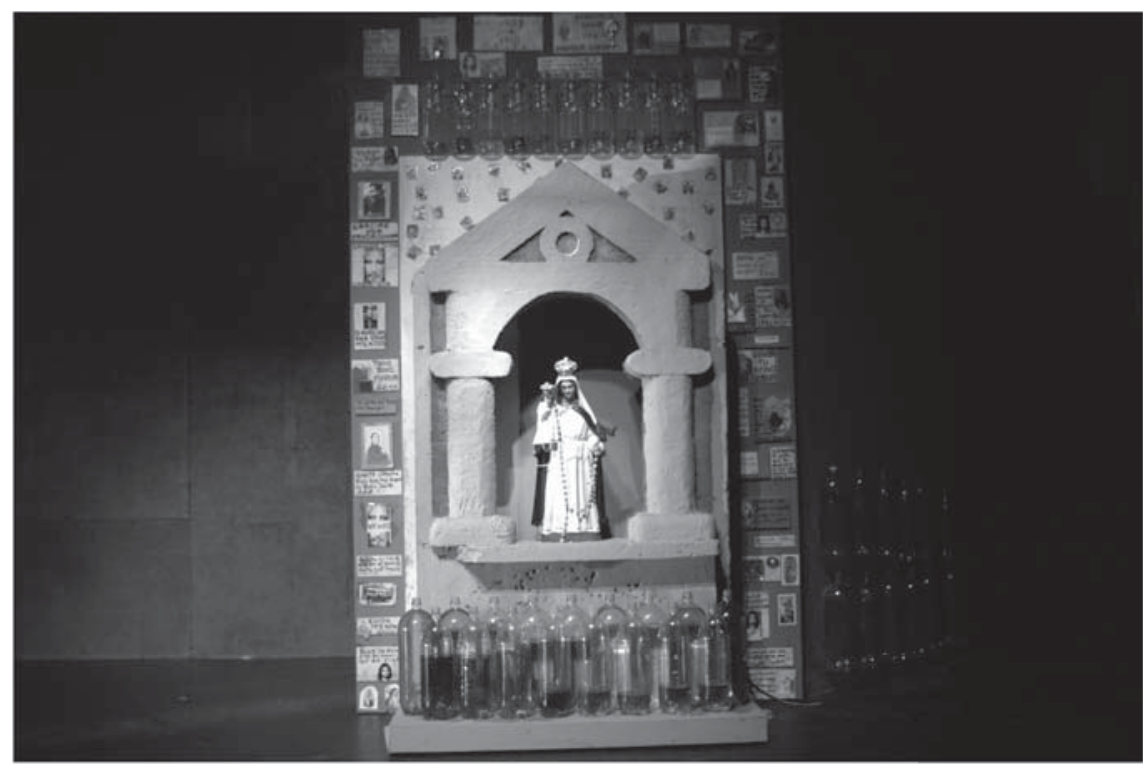

Fotografía 6: Prensa UC.

Botellas, flores, camelias, geranios, claveles, todo un espectro de pequeños dardos que son lanzados en el voceo diminuto de la niña, a la cara de los automovilistas, y lo que es peor, a los espectadores, como souvenir diríamos, como un traer a la memoria, pero también como la entrega de un presente, en este caso molesto, incómodo y hasta incomprensible.

Las flores son expuestas en una florería ambulante, hecha de tarros y repisas que en un segundo sirven para el traslado de esta mercadería que es también un pretexto y que al segundo siguiente es el trono de esta aspirante a puta cara. Un trono, una reina, unos deseos que se exponen, se declaman, y son bruscamente desbaratados por el ¡ahhhhh! 
también tan chileno, con el cual se desbarajusta toda solemnidad. En Chile, ha escrito José Joaquín Brunner, "al no haber una sola identidad, al no haber algo así como un ser nacional, una imagen arquetípica de lo chileno, una figura de lo nacional, la retórica patriótica es (entre nosotros) mal vista y peor recibida, la escuchamos con escepticismo, nos suena hueca, a lo más le atribuimos un valor instrumental» (Brunner). Este ;ahhhhh!, luego, es el grito repetido y reiterado a través de toda la obra y que junto al güena huacho señalado ya con respecto al expósito, nos sitúa a medio camino entre la gravedad de las circunstancias y la incomodidad en la que nos puede poner una lágrima a destiempo o un silencio que no sabremos cómo llenar, con qué frase completar, viviendo como sociedad, un verdadero pánico escénico.

Pero la niña no sólo hace referencia a su capacidad de venta, a sus evocaciones sentimentales (Carlos, su amiga Laura que come pizza a cambio de sus besos), sino también a las imágenes de niños perdidos impresas en cajas de leche. Cajas que viajan desde la empresa que traslada y encartona la leche, hasta la vida cotidiana de miles y quizás millones de personas; pasando por el almacén o el supermercado.

Imágenes fotográficas colocadas como el signo más elocuente y decisivo de la industria cultural, toda vez que se asiste acá, no tan solo a la reproducción mecánica de la imagen de un rostro y de unas señas también biográficas, sino fundamentalmente a la industria que recoge, procesa, interviene, envasa, apila, distribuye y comercializa un producto, en una cadena interminable de reciclaje económico.

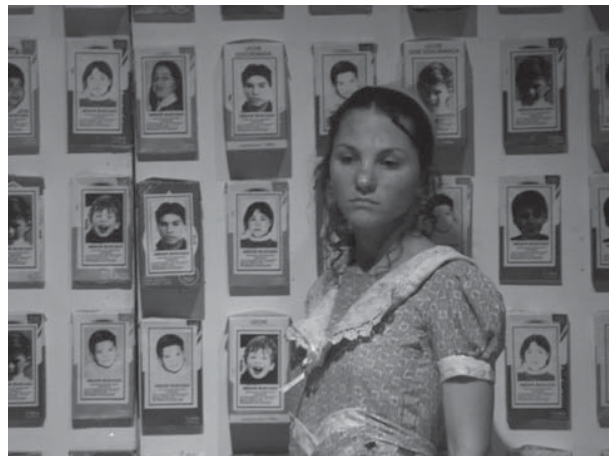

Fotografía 7: Carlos Espinoza

Así, sin más, la niña que se-vende, se instala en el centro de unas cajas adosadas a un muro gris, que en un juego múltiple de paneles giratorios, desmenuza el collage de los niños no encontrados, en donde no deja de resonar la macabra historia de los desaparecidos forzados por un régimen de terror que finalmente no supo hacer ni la guerra ni la paz. De allí, creo, que surja ese $\mathrm{NO}+$ tal cual un graffiti o una impresión tipográfica - figura, forma, escritura - urbana que alude a la historia de larga duración, pero que para nosotros, para quienes todavía tenemos muy fresco el recuerdo de los hechos acontecidos en el Chile de hace 30 años, resulta la historia más inmediata. 


\section{EL NIÑO OBRERO}

Mi cabeza me enseñó, cuánto eran dos más dos... alcancé a ir dos años al colegio, canta de nuevo en ritmo y gesto hip-hop el pequeño y grande niño cristalero, es decir, un trabajador infantil de una industria de fabricación de botellas, garrafas, chuicas y vasos, que fue parte de toda una práctica empresarial corriente en el Chile de las primeras décadas del siglo XX. Niños cristaleros contratados como mano de obra barata y menos conflictiva desde el punto de vista de las reclamaciones salariales o de las condiciones de trabajo; lo cual no les impidió, en su momento, hacerse parte de las huelgas que regularmente estallaban debido a esas mismas condiciones de trabajo.

Niño muerto, añorado por la niña que vendía flores; personaje doblemente expuesto: a la tierra o mejor, al espacio de un mundo de purgatorio y al espacio o dimensión de la ánima en pena. ¿Dos veces muerto? Una como todos los otros personajes de la obra, pero además muerto al interior de ésta misma por los acontecimientos sociales que él mismo relata. Atropellado por un tranvía mientras arrancaba de los carabineros que lo perseguían por su capacidad de convocatoria a la huelga, golpeado por un padre accidentado, olvidado por todos y solo recordado una vez muerto a través de los sueños y las flores que se le dejan en su animita. Una animita que esta vez se imagina hecha de cristal, aunque como hemos visto las botellas son ahora plásticas.

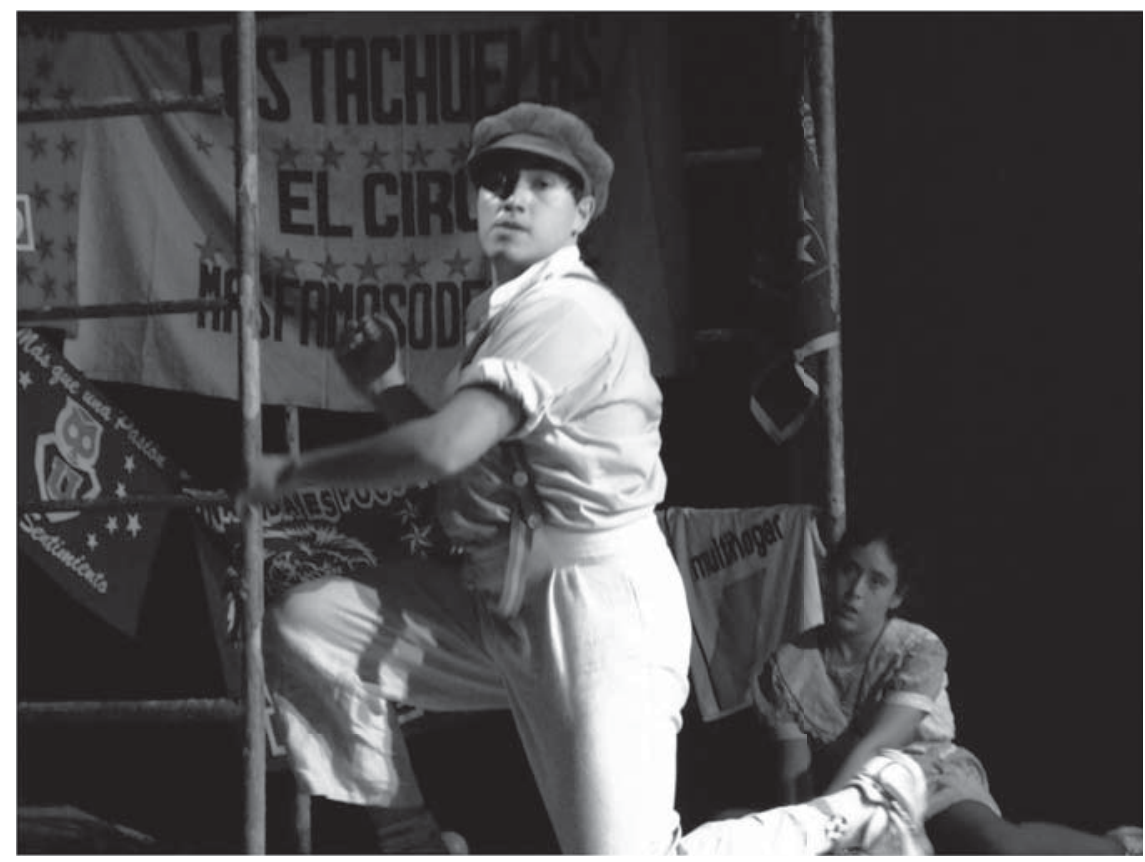

Fotografía 8: Carlos Vázquez Lomelí 
El niño obrero es magistralmente personificado por Pinilla, el que al parecer es un animal del teatro, un chacal de la cultura diría Anita González. Un chiquillo, un personaje y un actor que parece mirar a través de unos cristales y de unas formas, que menos que oponerse a su vida laboral del menor de edad que trabaja descarnadamente como obrero, le permiten el sueño de la opacidad relativa del vidrio.

Pinilla actúa dentro de la acción del trabajo actoral, evoca a su padre, a su patrón; transmite unos hechos trágicos y sociales con la voz del relator radiofónico de fútbol, acompañado del expósito que ha dejado de serlo.

\section{EL NIÑO MALHERIDO}

Permítaseme una nueva anécdota muy personal: la perra de mi hijo llamada Chiquitina, guacha por antonomasia, quiltra chilena, recogida de la calle, adoptada por el más banal, elocuente y gratuito cariño por los animales, dice cada vez que la tomo en brazos (a través de mi boca evidentemente): yo le decía hola padre, al que decía ser mi padre. De este modo el niño malherido dialoga con el expósito — y en mi mente con esta perrita- al plantearse este último la idea de haber sido tratado como un cachorro malparido.

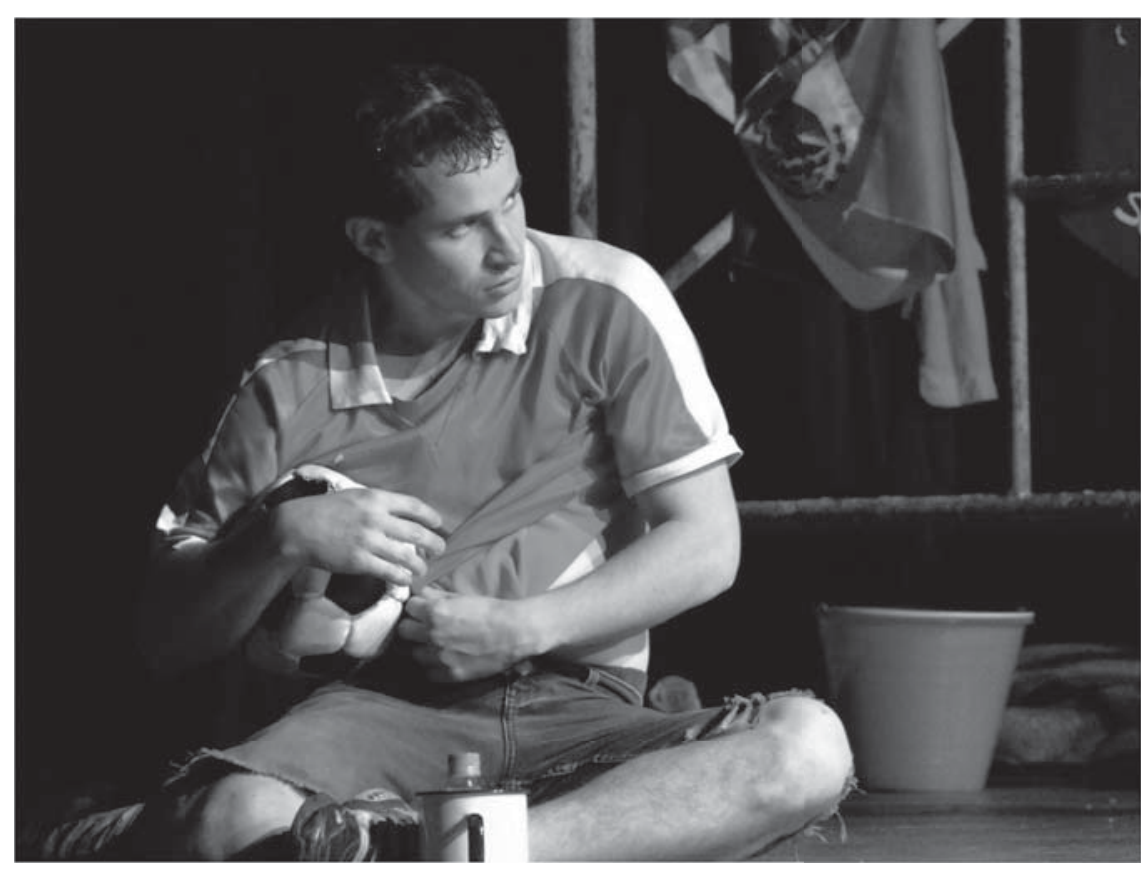

Fotografía 9: Carlos Vázquez Lomelí 
Niño guacho, maltratado, burlado por el destino y unas condiciones de una sociedad que nada le dio y que él le devuelve con el gesto épico del paseo de la bandera chilena. ¿Un gesto de burla? No, más bien una contorsión irónica, una figura retórica que le recuerda al público que ese signo nacional y compartido es, justamente, un emblema que nos une, pero que también nos divide y separa, hasta ahora, inexorablemente.

Guille sabe tomarse el personaje, sabe recorrer con su capacidad de un actor que experimenta con lo nuevo, y no lo digo por su talento hacia la vanguardista idea de lo nuevo, sino más bien por su juventud; por su capacidad de representar la actualidad más actual.

El guacho malherido evoca a su vez a su padre y a su madre, a los que decían ser su padre y su madre, al Willy, al del labio leporino, a aquel que será también maltratado, quizás como una manera de expiar sus propios sufrimientos. Vestido con la camiseta de un equipo de fútbol, se detiene para cantar en music hall o en rap en una amalgama tan propia del teatro y que hoy llamamos menos por consistencia teórica que por moda, post modernidad.

El niño malherido contagia su sufrimiento, cierra la obra con su llanto, su ahogo, sus caricias y besos para con la niña de las flores sin dejar nunca de mirar de frente al espectador. Lo inquiere, lo escudriña, lo desafía, logrando que más de alguno se revuelque en su asiento, para terminar, en pocas oportunidades, llorando por los ribetes melodramáticos que también la obra sabe poner en juego. Él también baila, quiere parecerse al expósito, se pelea con el niño obrero los besos gratuitos de la niña que vende flores. El niño malherido sonríe y finalmente se duerme para despertar una y otra vez en la pesadilla de la vida misma convertida en teatro, en memoria y en historia desde estos modestos ademanes.

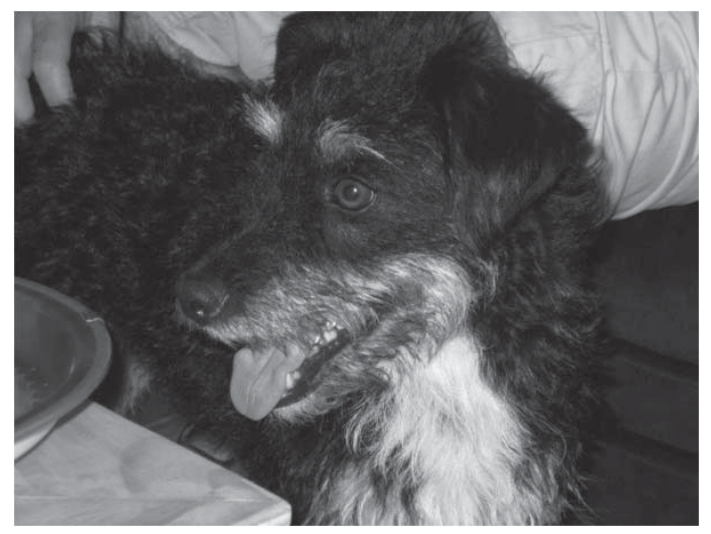

Fotografía 9: archivo personal Patricio Rodríguez-Plaza

¿Es La cruzada de los niños una gran obra de teatro? No lo sabemos, sólo puedo corroborar el éxito, los aplausos y hasta los llantos que suelen aparecer cada vez que se ha presentado en público. Una obra hecha de retazos, de pedazos dejados esparcidos por ahí por la ciudad comunicacional de la que dice ser expresión y prolongación.

Un trabajo que se inició y quizá nunca dejó de serlo, como experimento, como montaje siempre susceptible de acomodos, de retrocesos, de añadiduras creativas, que alcanza puntos altos de conexión con matrices culturales variadas. 


\section{REFERENCIAS}

Aguilera, Juan. Informe final-Proyecto DIPUC 89/005E. P. Universidad Católica de Chile. Diciembre. Medio impreso.

Bahamonde, Farriol, Rodríguez-Plaza. "La bandera: creación e identidad en el arte chileno contemporáneo». Cátedra de Artes 1 (2005). Medio impreso.

Baqué, Pierre. «Algunas preguntas, reflexiones y comentarios sobre una práctica universitaria de investigación en artes plásticas». Cuadernos de la Escuela de Arte 1 (1996). Medio impreso.

Brunner, José Joaquín. «Esta frágil materia suspendida». Un espejo trizado. Ensayos sobre cultura y politicas culturales. Santiago: Flacso, 1988. Medio impreso.

Castoriadis, Cornelius. La institución imaginaria de la sociedad, Vol. 1. Marxismo y teoría revolucionaria. Buenos Aires: Tusquets Editors, 2003. Medio impreso.

Cuadernillos, La Cruzada de los niños. Santiago de Chile: TEUC, 2006. Medio impreso.

Féral, Josette. Teatro, teoría y práctica: más allá de las fronteras. Buenos Aires: Galerna, 2004. Medio impreso.

Jauss, Hans Robert. «Estética de la recepción y comunicación literaria». La formación del crítico teatral II. 1990. Medio impreso.

Pavis, Patrice. Teatro contemporáneo: imágenes y voces. Santiago: Lom, 1998. Medio impreso.

Richard, Nelly. «Las coordenadas de producción crítica que sitúan mi trabajo». Aisthesis 21 (1988). 25-29. Medio impreso.

Rodríguez-Plaza, Patricio. «Apuntes críticos desde La Cruzada de los Niños». Apuntes 128 (2006). Medio impreso.

Recepción: 2 de junio de 2010 Aceptación: 30 de junio de 2010 